\section{Pas de Deux}

\section{Accompanying the Other}

Clarisse Labro

ALICE EPFL

Darío Negueruela del

Castillo

ALICE EPFL

\section{ENTRÉE/PROBLEMATIC}

This article develops the current state of an ongoing research on a pedagogical exercise in Architectural Design Studio for 1st year students. It is based on the conversation - dialogue between the two authors, who with different profiles and roles, have found joy in discussing the complementarity of their views in enriching their pedagogical and research strategies. The article is primarily, but nor exclusively, concerned with their teaching and academic activities at the EPFL in Switzerland.

We have entitled the article Pas de deux in a clear and unambiguous reference to dance. The title appeals to an image that goes beyond how aesthetically pleasing it might be to imagine two elegant and capable performers. In this sense, it responds less to the evocative image of a perfectly performed synchronization than to the deeper associations of interdependence, dynamism and unforeseen novelty. We dare to borrow the term Pas de deux as a way of naming a capable analogy for describing a mode of interacting and accompanying the other in the voyage of studying, teaching and practicing architecture. It stands in opposition to other explicit or implicit teaching models where fixed roles within a clear hierarchical scheme and a "simple" transmission of acting tricks (disguised as knowledge) is performed. In contrast, Pas de deux involves the collaborative tackling of uncertainty, with an acute importance given to care and attentiveness to the other, as that which is crucial for envisaging our own future moves.

The "Pas de deux" is, a priori, a dance for two performers. For this article, the two performers are an analogy for the journey into the intertwined identities and roles of those partaking in the teaching/ learning experience. This dance happens at different levels, involving not only the teacher and the student but also the practitioner with the teacher, or the citizen with the academic. One might argue then: "It isn't a Pas de deux, but two solos?" Except that the two roles are intertwined and feed one another - therefore, the dance wouldn't exist if it were two separate solos. In addition, the dancer never wears a single identity but multiple, travelling between identities. One might ask: "Maybe they are simply following a well-arranged choreography? A composition and arrangement of dances?" Not really, as the outcome is not pre-arranged and the two performers evolve their dance contingent to one another. The "deux" word is crucial as it is a two-sided interaction and the "pas" relates to the stepping along one another, dancing with one another. The pas de deux is always a pleasure to watch as it embodies conversations, difficulties, arguments two bodies have while moving rhythmically, often to music

This article introduces yet another mode of analogical thinking, using the arguably evocative image of dance as a tool for emancipation. A tool, an image, an analogy, to be used in reconceiving architectural pedagogy beyond what we deem an inadequate pedagogic paradigm that focuses on (1) the emulation of established successful recipes for design instead of on a critical assessment of the design process, (2) the excessive importance of the 'hidden curriculum' in architecture schools, which place too much emphasis on identity closure and (3) an ill-conceived use of learning aids and dismissal of the dynamic structure of both teaching and learning. 
For the sake of coherence, we have also structured the present article as both a dance and a dialogue composed of two voices, which at times join into one and others may unfold into many more. The article is thus composed of three parts, where the second part, entitled "2. Development", sees a first voice narrating a short story that captures and synthesizes a scene of interaction between teacher(s) and student(s) which contains what we consider a relevant episode worthy of deeper reflection and analysis. As a reaction, a second voice reflects upon the ingredients of such a scene in the light of broader problematics of pedagogy and architecture. This structure aims at opening up lines for further analysis, which are then enumerated and made explicit in the conclusion. This article makes use of different registers, a more narrative one that flirts with ethnographic observation and self-reflective practice, and a second one articulating those experiences into an analytical framework. And yes, we know, proposing these questions to navigate through some examples of a 1st year studio is not easy nor without risk.

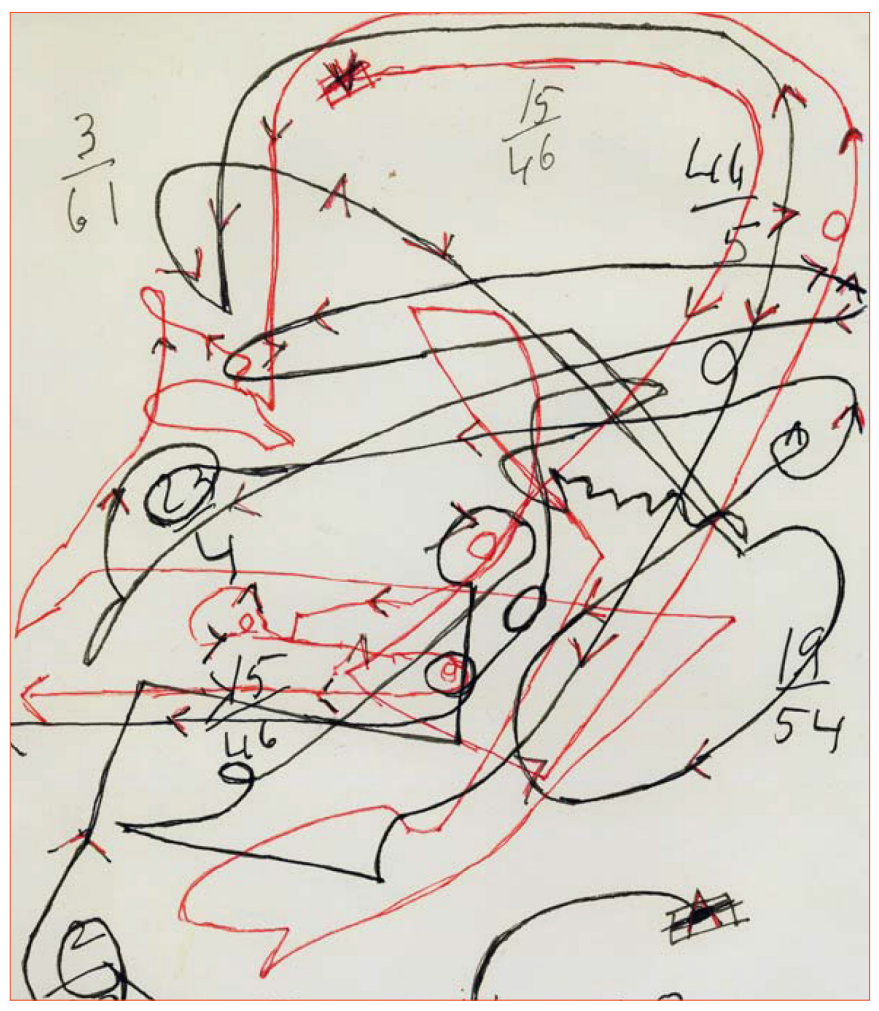

Figure 2. Interaction, synchronized contingency and uncertain beauty (from: Merce Cunningham Dance Company Decor \& Lighting by Dove Bradshaw 1984 - 1991. A Limited Edition)

\section{ADAGIO / DEVELOPMENT.}

\section{STORY 1: THE STORY WITH TERESA}

This story takes place in the heart of the building we occupy with our students. "We" are the instructors of the architectural project for first year students at the Ecole Polytecnique Fédérale de Lausanne in the ALICE laboratory in Switzerland. We are ten and are in charge of around one hundred and seventy students all together. We have taken over two floors measuring each $\mathbf{4 0}$ meters in length and 10 meters in width. The students have organized the space according to a plan we had drawn out for them and are installed by groups of a little under twenty. Each one of us is responsible for one of these groups. In the north east corner of the floor I inhabit, my colleague Teresa has her "studio". Mine is opposite hers at the south west corner. Between us, two other groups are installed. Teresa is almost 40 years old, studied in a prestigious British school and has been teaching Architectural Design in this lab since several years. This is the first year we meet, as she had taken some time off during which I was hired in the laboratory. Teresa and I connect on many levels, the first obvious ones being our age, our studied architecture in English and our shared sense of humor. We are also mothers who commute to Lausanne every week to be with our students. The story will lead back to the relationship with Teresa, but the organizational and intellectual context deserves to be described further. Indeed, the story with Teresa is of course part of a bigger one and they feed one another.

The ten instructors that we are form a team. This team is reinforced by others in the lab. Doctoral students, thesis advisors, administrative assistant, "design researchers" and other "scientific" guests. The relationships we develop with our colleagues are intense and enriching, often becoming beautiful friendships. These bonds are built in a similar way to the ones we had made during our own studies: many hours spent together exchanging over spatial ideas and how to construct them. Here, though, we are a smaller group and our lives are not solely happening in the space described above. Our weeks are rhythmed by train rides, our roles toggling between studio architects, pedagogues and, for some, parents. We go from a very direct and frontal contact with our students to a more distant one with other professionals. The subject of our conversations varies from the articulation of a somewhat wobbly idea and how to make it clearer, conceptually stronger with our students to sometimes the opposite: how to disguise an idea we are totally convinced of into a more reasonable proposition adapting to our clients desires and needs.

Being an adult-architect in a small teaching team surrounded by almost two hundred first year students is incredibly stimulating, both as a practitioner and as a pedagogue. It gives one the opportunity to re-immerse oneself into a broader architectural study. Having had the time to practice our "métier" in several ways for some amount of years has given one the perspective needed to understand how to guide an exploration; what really is fruitful to survey? Teaching gives a pedagogue the opportunity to study without a specific built conclusion in mind. The project is the student's and ours is to accompany them. To accompany, not only does one need to be passionate about 
architecture, but also curious to understand others, to listen. It is this ability to listen that encourages a pedagogue to dive into an intellectual research without any other purpose than to be better informed to guide others. Teaching the practice offers one a reminder of a primary reason why he/she was drawn to this subject in the first place. To be creative with and for others. Not alone and not exclusively for others. WITH is the key word we are underlying here. It is at the root of this Pas de Deux idea. It is a revealing concept for us as it speaks precisely to what our métier is all about, as practitioners or as pedagogues. The Pas de Deux is a dance during which we are able to perform movements, to transmit emotions that are un-transmittable without a partner. Without that "lift," without this reaching out/ "main tendue" (in French), to support, to accompany, this form of choreography wouldn't exist.

When we are with our students, the days go by very quickly. It seems often that there isn't enough time even though in reality we share that same space together for nine hours one day and four to five hours the morning after.

The atmosphere within this creative space varies according to the seasons and the projects. According to the light that fills it but more specifically, according to the energy of the students that inhabit it. The way they move through the space, the way they approach their drawing desk, drop their bags, greet each other - it all has an impact on "the studio." This atmosphere is as palpable as a hand woven wool fabric when touching it with your fingers.

This ambiance, we have the length of the floor to feel it, to prepare ourselves to dive into it. This crossing, depending on the pace of our walk, can take between 30 seconds and a couple of hours. It lasts longer when we take the time to look at the students' works, to go talk to students we don't have in our group and therefore know less.

Teresa and I have shared that crossing several times together. It was a stroll rhythmed by a dialogue on what we were observing and also about how our teaching day was going and how we were foreseeing its development. It was like traveling in a movie. A long and continuous movement, without a freeze frame. Maybe by the end of it, a static moment to end our discussion, to comfort one another that we knew where we were headed. It was a change of position as well, from walking next to one another to facing each other and looking into each other's eyes - to draw a synthesis on the structure of our teaching day. This synthesis like the end of a musical movement or an intermission between two acts of a play. Then a short silence. The curtain falls, change of décor, the curtain rises, act 2 begins. The first act was with the students, so is the second one. They haven't heard the soundtrack, they had their own interlude, the dance can begin again...

This trip through the work space is crucial as it allows to take some distance, evaluate the situation, even for a short amount of time. This perspective gives a more global vision on what is happening throughout, for a bigger group of individuals. Just like a movie director or a choreographer must oscillate between the stage and the orchestra during the length of the rehearsal period. The teacher does a similar back and forth - constantly. There is no rehearsal or show time.

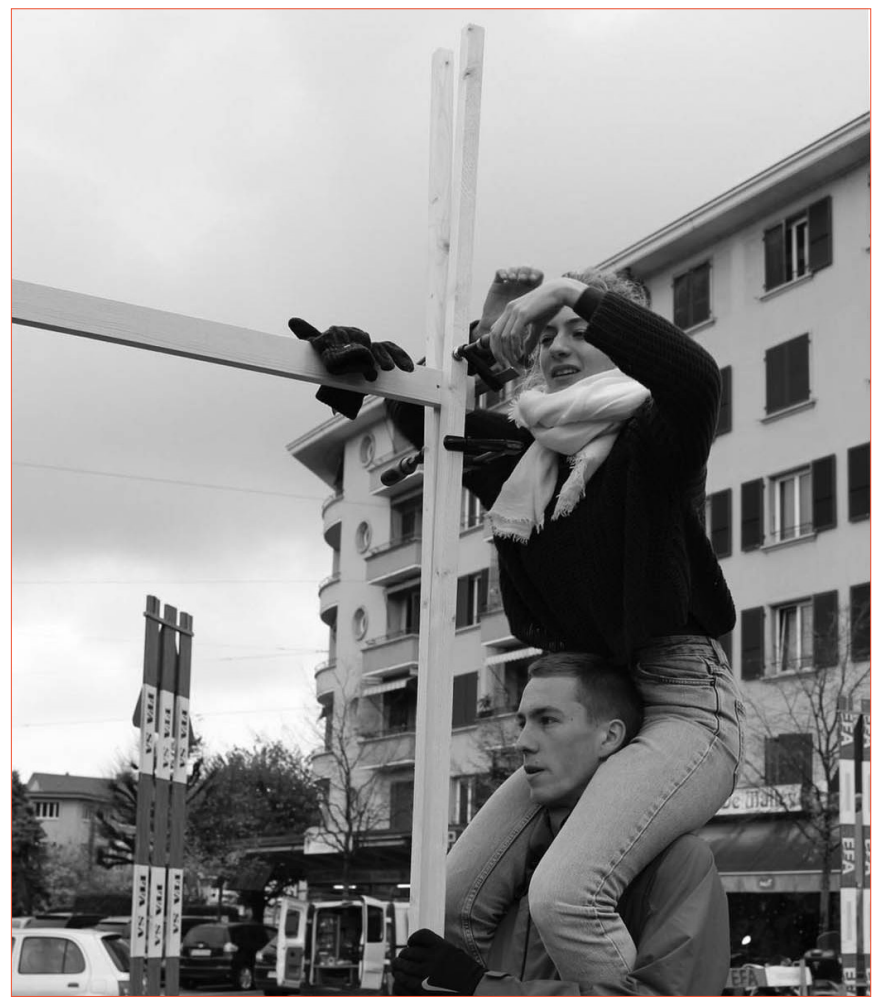

Figure 2.Together yet autonomous. (ALICE EPFL 2018)

It is an ongoing performance. The pedagogue has to be the mobile part of the lens with the variable focal, he/she has to move to modify the focal distance. This modification invites one to see at every scale and allows one to be flexible. It is this flexibility which permits the ability to listen. Permits the reflection within the action. It is thinking through sensations. This voyage, this dance is also the foundation of a relationship. The ground upon which one can understand the other, his/ her approach, ways of being as a teacher. It is a transmission moment between colleagues reminding us that this métier is not to be performed alone.

\section{VARIATION / REACTION1}

In this episode, we identify the importance not only of the formation of identity through a shared time and space, but also that of the development and necessary articulation of a series of multiple identities. In such articulation, we discover, resides a key for the equilibrium between the personal recognition in a group's shared values and ways of doing with the independence of mind needed for critical enquiry. But what are the precise moves that allow for such coordination in the intense and attention demanding atmosphere of an architectural learning environment? How can we pin-point the gestuality that marks the development of autonomy? Perhaps, we can begin by considering gesture as an index of how certain modes of interaction already contain and may give birth to 
modes of sociality. This, we contend, is important for it turns the analytical exercise away from a simple survey of action (and reactions) and closer to an actual study of how a particular structured society emerges out of the studio ${ }^{1}$.

In that respect, throughout the studio we witness an evolution that inhabits a fertile tension between what constitutes a community, with its emphasis on mutual recognition and identity closure, and, in contrast, a society. The later, allowing for the freedom to reinvent oneself, and yet organically functioning on the grounds of complementary and not identical roles, is not an obvious evolution within the studio. More often than not, architectural education environments seem to favour the cultivation of identity on the grounds of a socially determined image of the architect or designer. Following the late but developing literature on the topic, we suspect this is based on the pervading forces of the hidden curriculum, which very strongly shape the identity formation of many architectural students (and thus of those who teach architectural design) ${ }^{2}$. Indeed, researchers have indeed warned us that "(...) failure is not necessarily failure to know something, but failure to be something" 3 .

Thus, in addition to learning architecture, what also remains crucial is to become an architect. And such development of an identity closure among students seems to be facilitated by the intensity of the time and space shared during the studies, among other factors. In other words, and in the best of cases, a community of practice 4 . However, despite the common identity to be developed based on shared practices, which in turn shape a specific shared world view, there seemed to be a multiplicity of communities in constant formation during the studio year. Educators might also be parents, and practitioners, and the constant renegotiation of these identities in the various environments perhaps also allows for unforeseen spillover effects and contagions. As well as for shifts in perspective that might allow for a more reflective practice.

It becomes clear to us that, in order to overcome the downsides of homogenization and indoctrination that these practices risk, a necessary distance, a fringe of freedom is required. Such freedom need not happen in a vacuum, but properly scaffolded 5 by the group, the environment, as well as by the attentive accompanying attitude that is the base for the Pas de deux. This is exactly the crucial element we argue constitutes a veritable transformative learning environment, bearing enormous emancipatory potential. But emancipation from what? Who needs emancipation when we should be training highIy employable, efficient and compliant individuals ready to join the well-greased mechanism of the engineering and construction of our built environment?

Certes, the problematic of education and emancipation is large, rich and challenging 6 . It has widely been argued that "(Architecture), Planning and Urbanism cannot escape the same extractive scheme of the capitalist system that frames it (...)"7, which directly points us to the difficulty of even conceiving an emancipatory pedagogy within the frames of our societal setting. We share the idea that the logics of destitution are not limited to the production of physical structures like urban tissue ${ }^{8}$, but also encompass our own living experiential space (including our spaces and practices of education), framing our views on the future. How can we disarm the fundamental malaise at the core of contemporary cognitive labour? Could Pas de deux, with its emphasis on attentive presence, careful coordination (and here the words are not chosen lightly) be capable of putting forward another model for all of those things mentioned above? Or, could it at least simply change our frame for being able to become more sensitive to softer things than the perceived hard-core architectural quality of the results?

\section{STORY 2: THE STORY OF THE ARCHITECTES ANONYMES}

There are sixteen architectes anonymes.

Sixteen young adults, first year architecture students I have been teaching for a semester already. Their studio space is large and has windows on either side of its width. They each have a drawing desk, and shared tables where they can cast plaster or cut and assemble wooden models. As a studio instructor, I am with them, in their atelier for a day and a half every week of the school year.

We meet again, after a project they developed in pairs and after the presentation of which, the teaching team picked one or two to be the starting concept for a bigger group effort. That design is to be built at a 1:1 scale by the end of the semester on a given site. As an educator, I am to choreograph a dance for sixteen young architects. In order for the students to learn with pleasure and desire to challenge themselves throughout the whole process, they are to become one tight group, to develop a common project on a complex site. As an instructor, I am to converse with a single troupe of sixteen thinking heads and bodies. Sixteen personalities that move differently, that have different skills yet must learn the same tools and how to use them by the end of the year.

How does one studio instructor become the thread that keeps the fabric all together? How can the teacher make each individual student commit to the group?

A bond was created between the students and the instructor throughout the first semester and hopefully it is strong enough that it can be trusted to last, to adapt and to guide. It is a bond based on trust. Just like when dancing with another, you have to trust your partner in order to keep moving together. The same confidence must be established between the students. There is no place for competition in First Year. Adulation and challenges have their role to play, as they are active motivation engines for students. The members of the group need to want to belong. It may be one of the first times an eighteen years old feels a sense of responsibility for a project and, by default, for others of the same age he/she is constructing it with.

I had asked the sixteen students to synthesize their thoughts on the review of the last exercise into a sort of written dream project they would do together. It was to be written in whatever "style of writing" they wanted. 
It had been a week since they were given the brief.

I decided to have us meet in a different space than our usual studio environment. It was in a "regular" classroom, where we moved desks and put a circle of chairs together. It took some time for the circle to be drawn cleanly. The troupe needed to be led and sometimes singularly be called out to help create the circle. Finally, we all sat down. No phones, no bags, just a paper with their stories on it and a pencil to write with. I had invited an exterior guest, a philosopher and playwright who had given them lectures throughout the year.

Sitting down in the circle - facing each other. There were some giggles, a little bit of whispering; I waited. It is essential, in that moment, not to lose faith in the experiment. Again, here one needs to trust him or herself that the students will want to "play the game." Finally, in a quiet moment, I explained to them what we were here for. They were to each read aloud their story. This is when, a couple of seconds can feel like several minutes. You can hear, see, sense every move in the room. The ones that are looking down, hoping not to be the first, the ones twirling from the waist down, as if the seat of their chair was not comfortable enough; the ones looking to their colleague's gaze to see if they were "in this together." One can feel the body heat go up by a couple of degrees in a matter of seconds. It could maybe be compared to "stage fright," except here, we are sitting together in a circle, not waiting behind a curtain for the lights to go on.

After three hours of reading and discussing the written pieces and their content, one student compared our reading circle to a therapeutic one. Much like the groups who meet to discuss and share their experiences with addiction and help each other through their struggles. I responded that we were not far from it, form-wise indeed, but we were lucky to be talking about spatial creations and sharing dreams rather than struggles. This time spent exchanging our voices, using written and spoken language as tools, was a privilege we had to honor by practicing it daily. Listening to one another was now one of their skills. Including their peers' voice in the project was a contract and the project was to be shared, not one's only and not "signed." They were listening. I used this momentum to speak about architecture for the people, not as a simple mark on a territory. The only trace they should be focused on making was in fact the absence of one - humility and respect to the broader context they were designing in. I explained that it started here in this room - every day, looking at each other and listening - caring for one another. Standing up, they agreed, and felt proud of the nickname I gave them at this moment: the Anonymous Architects circle. They instinctively put the desks and chairs back into their positions. Unlike three and a half hours prior, I didn't have to show them how to move their chairs. They just did it, autonomously.

\section{VARIATION RAPIDE / REACTION 2}

Embracing the Pas de deux analogy meant giving a breathing space to becoming. While other pedagogical models require emulation and the unquestionable role of the teacher as master or expert resides at the core of their teaching/learning model(refs), pas de deux demands a different and peculiar form of engagement. By accompanying students in their uncertain journey, learning to ask anew the matter of

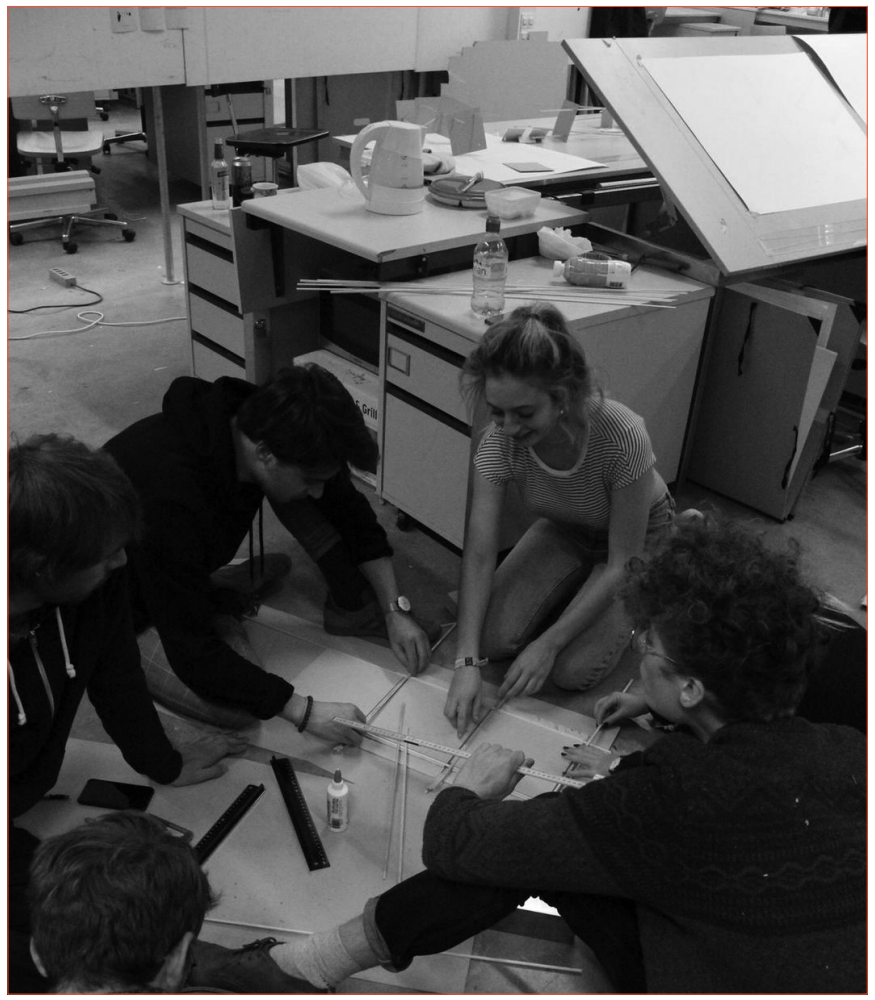

Figure 2. Circle of action. (ALICE EPFL 2018)

our learning and embracing their insecurities gave way to a sudden recognition of the potential lying ahead. This was achieved in a choral manner, side by side but also, and at the same time, in an autonomous and individual way. Embracing the uncertainty of a personal and professional becoming meant welcoming the other9. Not simply fellow students or teachers, but the other transformed self, awaiting at the turning of the next corner (challenge). And we learn from our learning that this welcoming of otherness and uncertainty is related to an attitude or attentive accompanying in solidarity rather than guiding, scaffolded by the dynamics of the interaction within the group.

\section{CODA/ CONCLUSION \& OPENING}

The widespread hegemony of Studio teaching in architectural design education seems, in broad terms, to be usually conceived within a combined framework of conventional expert knowledge transmission, and master role models. Questions of formation of identity as well as development of autonomy are largely overlooked and left to the workings of the pervading hidden curriculum and social inertias reproduced within the studio.

In contrast, we propose to conceive architectural education as the vehicle and the excuse to perform a transformative journey, a journey that can help us better understand not only how to better do with others, but to actually conceive, design and think with others and for oneself in genuine collaboration. A journey which through an iterative process of enquiry, trial, common assessment and re-trial is able to transform our identity beyond the hierarchical articulation of black boxes such as "user" "designer" "creator". Many voices have raised concerns about the over defining role of the societal structural forces 
shaping both the profession and our education system. It would be perhaps easier to subsume into a fatalistic pessimism. However, it is through a naively generous attitude that we start to get some glimpses of a way forward. A way of attentively accompanying students in their journey, respecting the unforgeable curiosity at the core of open enquiry and firmly grounding it on the most ephemeral of alliances, that of a genuine encounter of differences. This is, of course, but an ideal scenario. An ideal image, however, which we can, notwithstanding the imperfections of it first attempts, we can already feel contained in potential every time we recognize we have learned to accompany.

We believe an open and dynamic interaction between student and teacher has a deep, if often underestimated, effect on both the learning process and the personal identity transformation that accompanies the architectural educational experience. Our hypothesis posits the crucial role of the Pas de deux itself within the learning environment in enhancing our capacities to empathise and explore solutions. Capacities, we argue, that remain at the core of the necessary tool kit for any sensitive, ethical and civic professional that might be asked to contribute to the design of our common future.

Pas de deux emerges as a suggestive analogy for a different model for the teaching environment in architecture. With it we propose to place emphasis on the dynamism of the pedagogical performance and the interdependent becoming of the actors involved, enhancing the professional and personal transformation of teachers and students alike. This stands in stark contrast to other models based on emulation, like more traditional studio methodologies associated with the apprenticeship model we see being again strongly vindicated nowadays. The trajectory of the choreography of the Pas de deux mirrors the trajectory of change undergone by all participants within the learning environment. This is the result of a relationship based fundamentally upon open engagement, trust and honesty. All actors are fundamentally transformed, and it is in carefully and attentively considering and articulating all of this identities in contingent evolution, that this transformation can effectively be transformative in broader dimensions. Moreover, we argue that in combination with these qualities, the structure of the pedagogical set-up and the predisposition and availability of the educator in time and space are fundamental in transforming the students' attitudes and learning culture.

\section{BIBLIOGRAPHY}

Bingham, Charles, and Gert Biesta. Jacques Ranciere: Education, Truth, Emancipation. Bloomsbury Publishing, 2010.

De Lissovoy, Noah. 'Rethinking Education and Emancipation: Being, Teaching, and Power'. Harvard Educational Review 80, no. 2 (July 2010): 203-21. https://doi.org/10.17763/ haer.80.2.h6r65285tu252448.

Derrida, Jacques, and Anne Dufourmantelle. Of Hospitality. Cultural Memory in the Present. Stanford, Calif: Stanford University Press, 2000.
Dutton, Thomas A. 'Design and Studio Pedagogy'. Journal of Architectural Education 41, no. 1 (October 1987): 16-25. https://doi. org/10.1080/10464883.1987.10758461.

Kendon, Adam. Gesture: Visible Action as Utterance. Cambridge; New York: Cambridge University Press, 2004.

Lave, Jean, and Etienne Wenger. Situated Learning: Legitimate Peripheral Participation. Learning in Doing. Cambridge [England]; New York: Cambridge University Press, 1991.

McNeill, David. Gesture and Thought. Chicago: University of Chicago Press, 2005.

Palincsar, Annemarie Sullivan. 'Keeping the Metaphor of Scaffolding Fresh-A Response to C. Addison Stone's "The Metaphor of Scaffolding: Its Utility for the Field of Learning Disabilities"' 31, no. 4 (1998): 4.

Puntambekar, Sadhana, and Roland Hubscher. 'Tools for Scaffolding Students in a Complex Learning Environment: What Have We Gained and What Have We Missed?' Educational Psychologist 40, no. 1 (March 2005): 1-12. https://doi.org/10.1207/s15326985ep4001_1. Radford, Luis. 'Education and the Illusions of Emancipation'. Educational Studies in Mathematics 80, no. 1/2 (2012): 101-18.

Sevilla Buitrago, Álvaro. 'Urbanismo y reproducción social: Una introducción a su historia'. Cuadernos de investigación urbanística, no. 80 (2012): 7-56.

Stevens, Garry. The Favored Circle: The Social Foundations of Architectural Distinction. Cambridge, Mass: MIT Press, 1998.

\section{Notes}

1. Kendon, Gesture; Developing ideas contained in seminal works in gesture studies, like the theory of gesture as utterance by Kendon and the theory of gesture as Growth Point by McNeil. See McNeill, Gesture and Thought.

2. For one of the initial and most cited works in this respect see Dutton, 'Design and Studio Pedagogy'.

3. The Full citation revealingly reads the following way: "Anyone who has experienced any form of discrimination - because of race, sex, or ethnic origin- is only too aware that failure is not necessarily failure to know something, but failure to be something". Stevens, The Favored Circle.

4. Lave and Wenger, Situated Learning.

5. Puntambekar and Hubscher, 'Tools for Scaffolding Students in a Complex Learning Environment'; Palincsar, 'Keeping the Metaphor of Scaffolding Fresh-A Response to C. Addison Stone's "The Metaphor of Scaffolding: Its Utility for the Field of Learning Disabilities"'.

6. Bingham and Biesta, Jacques Ranciere; De Lissovoy, 'Rethinking Education and Emancipation'; see among others Radford, 'Education and the Illusions of Emancipation'. 
7. Sevilla Buitrago, 'Urbanismo y reproducción social'.

8. Sevilla Buitrago.

9. By welcoming the other we refer here in its most radical manner to the kind of unconditioned hospitality Derrida advocated for. Derrida and Dufourmantelle, Of Hospitality. 